\title{
Finite Element Analysis Based Structural Analysis of Stacked Heat Exchanger
}

\author{
Patil Tushar Vishwas ${ }^{1}$, Supale Jayant P. ${ }^{2}$, Vinaay Patil ${ }^{3}$ \\ ${ }^{\prime}$ (Mechanical engineering SKN SITS, Lonavala / University of Pune, India) \\ ${ }^{2}$ (Mechanical engineering SKN SITS, Lonavala / University of Pune, India) \\ ${ }^{3}$ (Vaftsy CAE, Pune-411028, India)
}

\begin{abstract}
A variety of heat exchangers are used in industry and in their products. A plate and frame heat exchanger is analyzed here for structural stability (stress optimization) using finite element method. Analyzed plate heat exchanger is a Waste Heat Recovery Unit (WHRU) that recovers heat from a hot gas stream while transferring it to a working medium.

WHRU in this specific case is used in the application of the Claus process which is used for Sulphur recovery. The Sulphur due to high temperatures is in Vapour form and is condensed to obtain elemental sulphur. At this condensation stage a WHRU serves dual purpose of condensation as well as energy recovery.

So WHRU is analyzed by finite element analysis method at working boundary conditions for identifying weak points in it. Modifications are made on weak points to reduce stress value and again WHRU is analyzed for same. The results are validated with the experimentation carried with thermal test equipment on the model.
\end{abstract}

Keywords: Claus process, structural stability, sulphur recovery, WHRU.

\section{Introduction}

1.1. Problem Statement: This is a stress optimization problem. In this a stacked heat exchanger with the provided dimensions is to be analyzed for structural stability using FEA software (ANSYS).

We can calculate the mechanical stresses developed in heat exchanger but thermal behavior (stresses and deformation) is very difficult to obtain accurately because of ununiformed distribution of temperature in the body. Many parts of the heat exchanger may fail because of thermal loading. Thousands of stacked heat exchangers are used in the Claus sulfur recovery units worldwide. Toxic gases are involved in Claus process. So, safe working of stacked heat exchanger without failure due to excessive stresses is necessary because safety is our prime importance.

1.2. Objective: Analyze the current design WHRU for stress optimization (structural analysis) using FEA. Identify weak points and suggest remedies for them.

\section{Literature Review:}

Khaled Saleh, Vikrant Aute done the optimization of plate heat exchanger (PHE) using multi objective optimization techniques. In this author compared offline approximation and online approximation assisted optimization to optimize PHE design. Author verified final results with CFD simulation. At the end author concluded that online optimization approach predicted better optimum design with high accuracy. ${ }^{[1]}$

A methodology to detect equivalent configuration is presented by Jorge A.W. Gut, Jose M. Pinto, "Modeling of plate heat exchanger with generalized configurations". Here author developed a mathematical model for simulation. In results he got the temperature profile in all channels, thermal effectiveness and distribution of overall heat transfer coefficient. ${ }^{[2]}$

An algorithm for optimization of PHE design is devolped by Fábio A. S. Mota, Mauro A. S. S. Ravagnani, based on screening method. Here number of plates is considered as optimization variable ${ }^{[3]}$ The reason for the effect on the flow pattern between the two corrugated plates was discussed by Zhang Guanmin, Tian Mao-cheng, in "Simulation and analysis of flow pattern in cross-corrugated plate heat exchangers". Here flow fields between two corrugated plates with different values of the corrugation inclination angle $\beta$ were simulated by using numerical methodology. The simulation results directly indicate that $\beta$ affects the flow pattern between corrugated plates, and the results are in good agreement with the experimental results reported by interrelated literature studied by the author. ${ }^{[4]}$

\section{Analysis Work}

For analysis purpose a 3-D model of stacked plate heat exchanger is needed. This model is developed using a cad software i.e. CATIA V5R14. The assembled model is shown in figure1. 


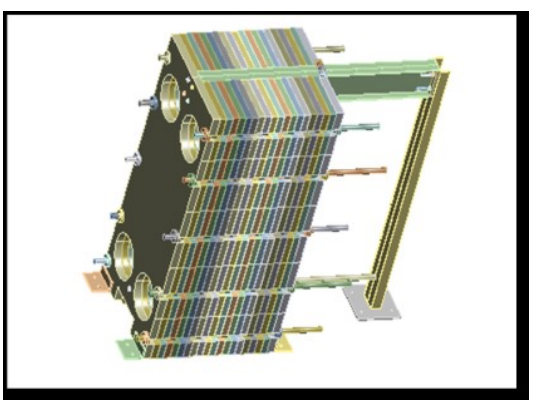

Figure 1 Catia model of stacked plate heat exchanger

The required boundary conditions for the analysis of heat exchanger are as follows

a) Inlet temperature of hot fluid $=140^{\circ} \mathrm{C}$

b) Out let temperature of cold fluid $=100^{\circ} \mathrm{C}$

c) Bolt compressive load $=2.5 \mathrm{kN}$

For the meshing of the element hexahedron and tetrahedron elements are used in ANSYS workbench. The meshing images are shown in figure 2 below.

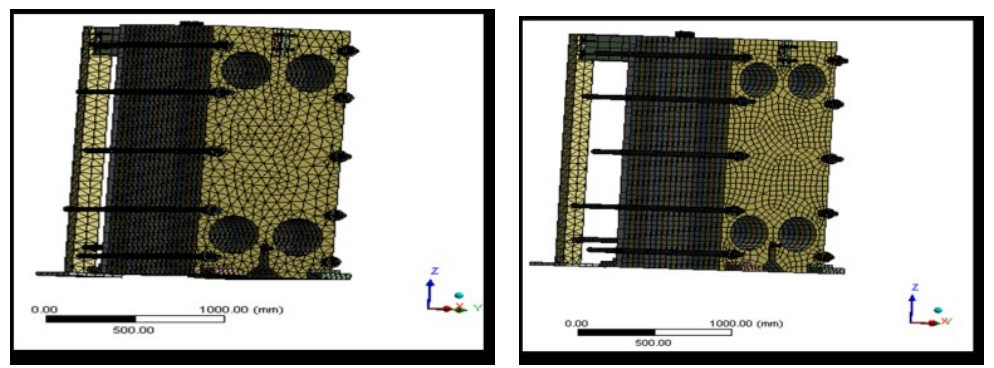

Figure 2 meshing of the model with tetrahedron and hexahedron element

The bolting load acting (boundary condition) on the model and thermal boundary conditions are shown below in figure 3. The analysis results in the form of deformation and the value of stresses developed in the model for both tetrahedron and hexahedron element for different number of nodes are shown in graph 1 and 2 below.

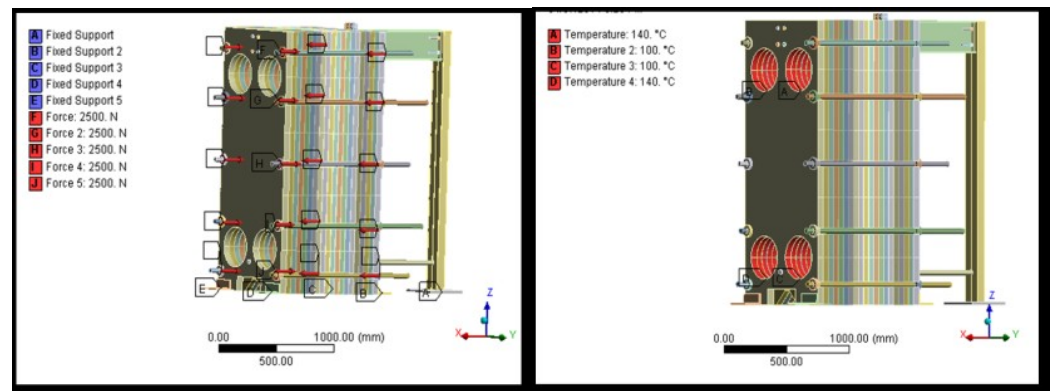

Figure 3 Bolting force and thermal boundary conditons acting on the model
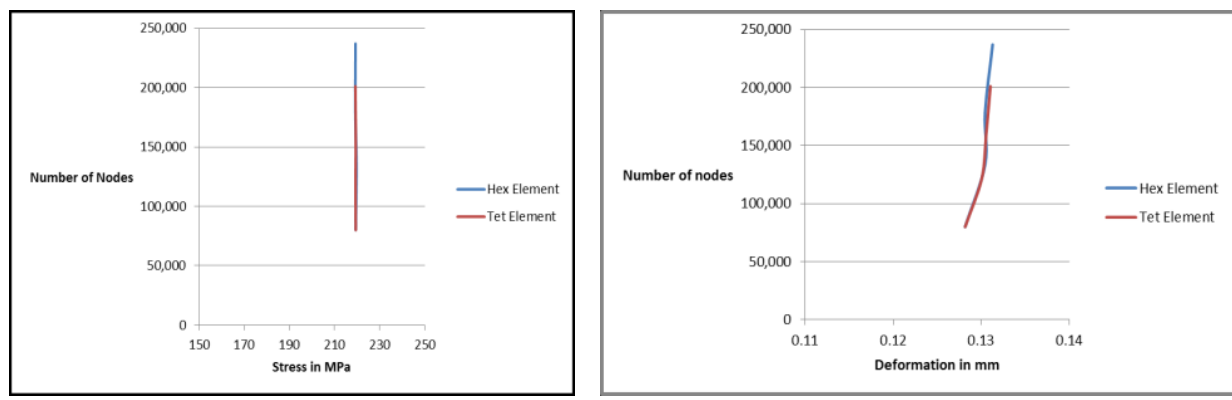

Graph 1 Comparison between hexahedron and tetrahedron element for bolting boundary conditions 

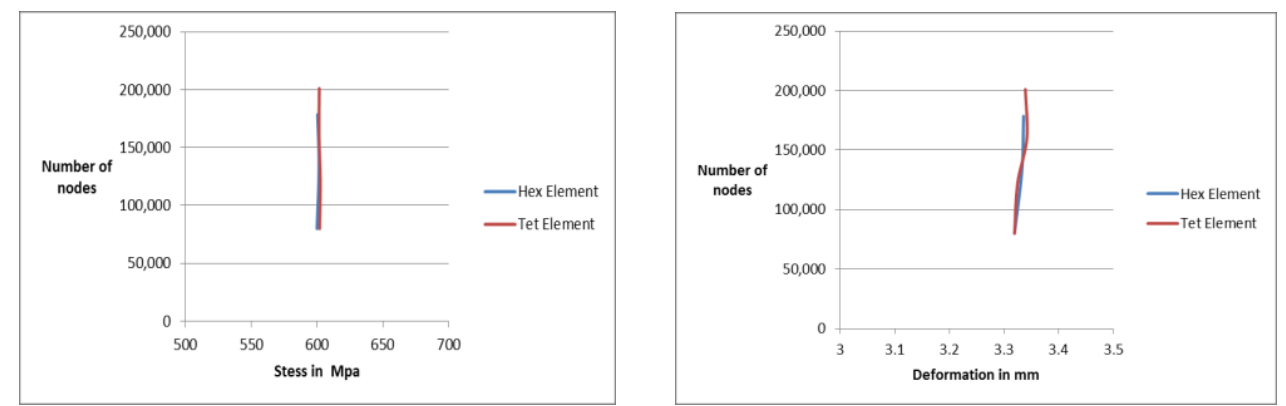

Graph 2 Comparison between hexahedron and tetrahedron element for Thermal boundary conditions

After analysis we find that for thermal boundary conditions the model fails at supports due to the excessive stress value. This failure at the supports is shown in the figure 4.

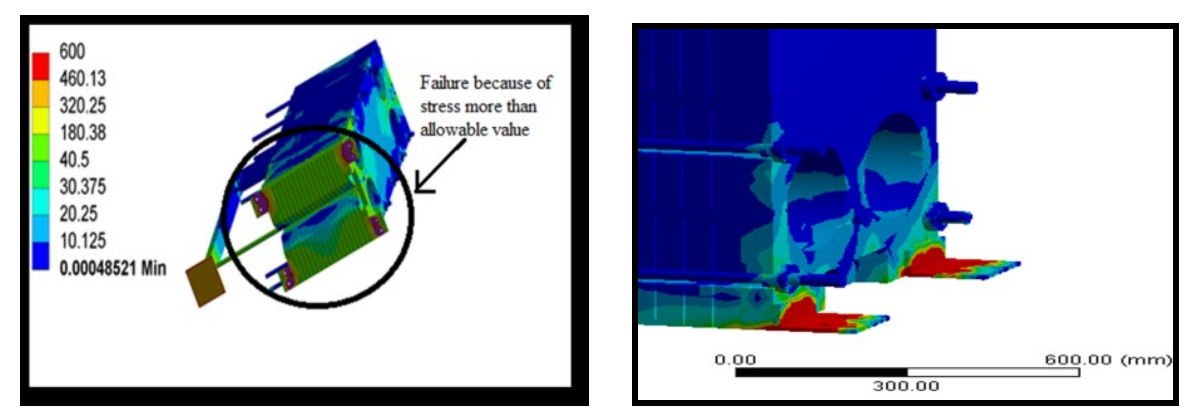

Figure 4 Failure at the suppoer after thermal boundary conditions

\section{Remedies on the failure parts in thermal boundary conditions}

The material used for analysis for fixing plate is structural steel. The value of allowable stress for fixing plate with structural steel according to ASME code section 8, part 5 is $412 \mathrm{Mpa}$. As stress value due to thermal loading that is temperature of the hot and cold fluids is more than allowable value, failure is occurred at fixing plate. So aim is to reduce (optimize) value of stress at fixing plate. Stresses can be reduced by increasing cross sectional area of the plate. So the new modified dimensions of the $\mathrm{L}$ shaped fixing plate for which the stress value is bellow allowable value are shown below figure 6 .

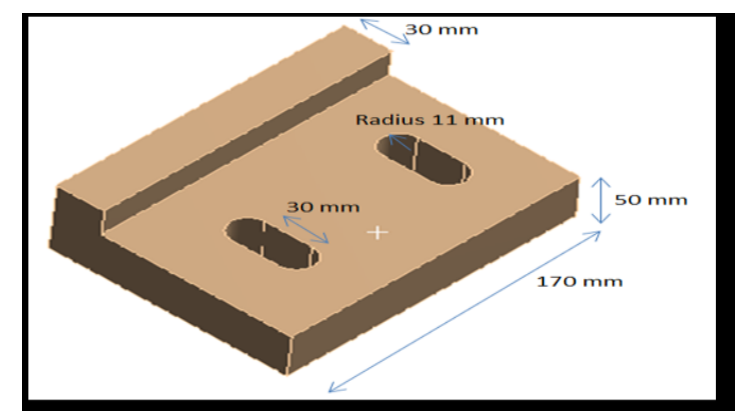

Figure 6 Modified geometry of L shaped fixing plate.

Similar to L shaped fixing plate, square plate is also need to be optimized for stresses value as stress value is more than allowable value. The modified geometry of square fixing plate is given in figure 7.

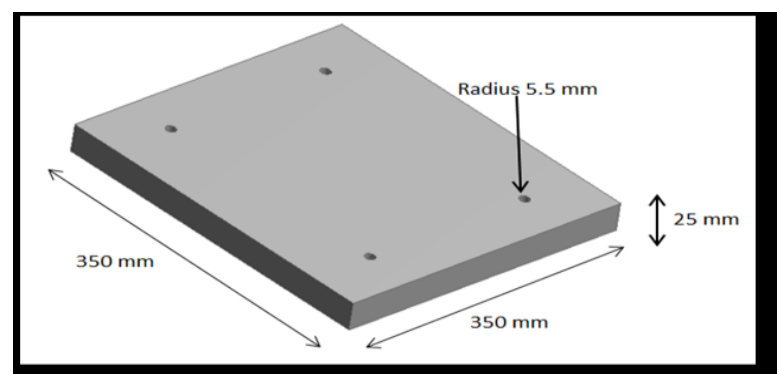

Figure 7 Modified geometry of square fixing plate 


\section{Analysis with modified Model}

When modified model is used for analysis we get the results in which model is safe for given thermal boundary condition. The reduced value of stress at supports is shown in figure 8 .

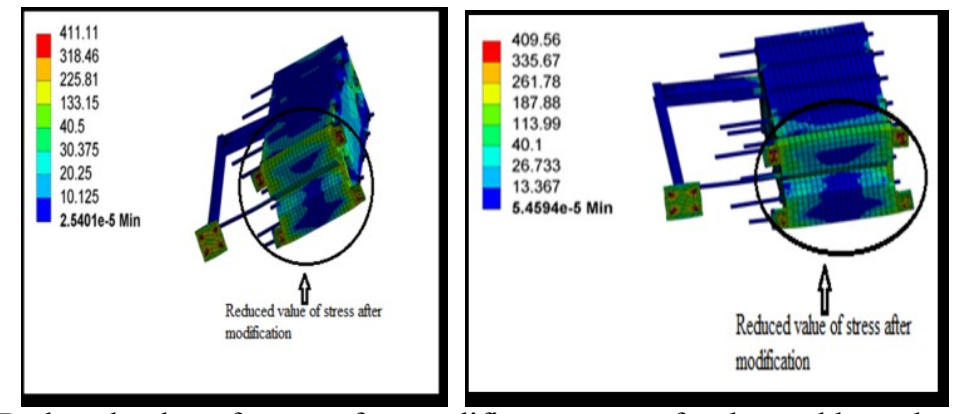

Figure 8 Reduced value of stress after modifing suppoert for thermal boundary condition

The deformation in the modified model for given thermal boundary conditon is shown below in figure 9 .

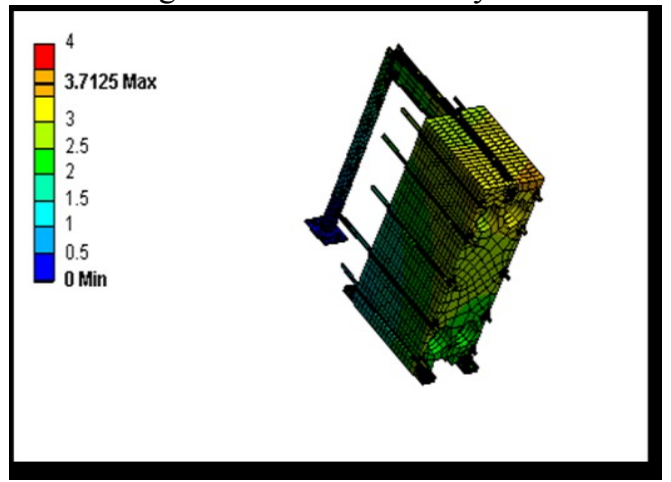

Figure 9 Deformation (in $\mathrm{mm}$ ) of the modified model for thermal boundary condition

\section{Experimental Validation}

For the validation of the results obtained by ANSYS software experimentation work need to be carried out on the model. Using Alluro Thermal Test Equipment heat exchanger is tested experimentally and then the results of this work are used for the validation of results obtained from software. The details of the testing are, ${ }^{[5]}$

a) Thermal imaging GOBI 640nGige

b) Microbolometer array

c) 8 to 14 micrometer sensitivity

d) Frame rate $640 \times 480$

e) L-0.05 Deg C

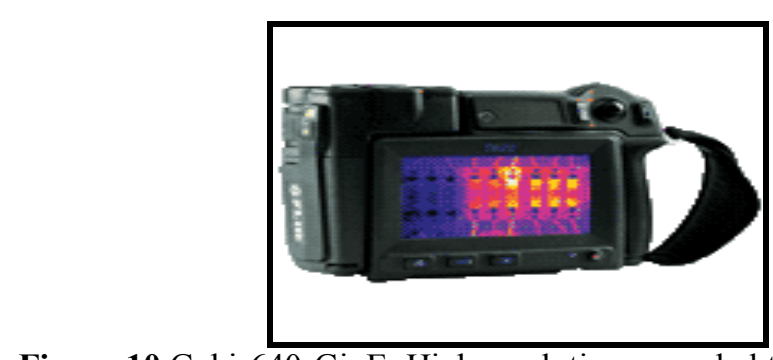

Figure 10 Gobi-640-GigE: High resolution uncooled thermal camera ${ }^{[5]}$

Readings of the experimentation are in the form of thermal expansion of the tie rod which is equal to $3.7 \mathrm{~mm}$ at $138{ }^{\circ} \mathrm{C}$. The results of experimentation are match up with the results obtained by the ANSYS. This validates the results of the software.

\section{Conclusion}

It is difficult to find out stresses and deformation of the material under non uniform temperature distribution, so for this purpose finite element analysis methods can be used. After performing structural analysis on stacked heat exchanger model for given bolting and thermal boundary conditions it is found that model is weak at its supports. When the supports are modified to reduce stresses model is found safe for both 
boundary conditions. These results of analysis are also matches with experimental analysis performed with thermal test equipment.

Stacked heat exchangers are used in huge number all over the world in different processes like Claus process, as they are more efficient. SO finite element analysis should be used as a tool for optimizing the design and various parameters of heat exchangers

In future there is also a scope for simulation of fluid flow through the heat exchanger using CFD or any modified simulation software for improving performance of heat exchangers.

\section{References}

[1] Khaled Hassan Saleh, Vikrant Aute,"Plate Heat Exchanger Optimization Using Different Approximation Assisted Multi objective Optimization Techniques" International Refrigeration and Air Conditioning Conference,2012.

[2] Jorge A.W. Gut, Jose M. Pinto, "Modeling of plate heat exchangers with generalized configurations" International Journal of Heat and Mass Transfer 46 (2003) 2571-2585.

[3] Fabio A. S. Mota, Mauro A. S. S. Ravagnani, “Optimal Design Of Plate Heat Exchangers” Chemical Engineering Graduate Studies Program, State University of Maringa, September 2013

[4] ZHANG Guan-min, TIAN Mao-cheng, "Simulation And Analysis of Flow Pattern In Cross-Corrugated Plate Heat Exchangers" Journal of Hydrodynamics Ser. B, 2006,18(5): 547-551.

[5] Liddiard, Kevin C. "The active microbolometer: a new concept in infrared detection". "Proceedings of SPIE". Proceedings of SPIE (2004) 5274: 227-238. 